\title{
Digital Twin of Fuel Cell Hybrid Electric Vehicle: a detailed modelling approach of the hydrogen powertrain and the auxiliary systems
}

\author{
Lorenzo Bartolucci ${ }^{1}$, Edoardo Cennamo ${ }^{1,}{ }^{*}$, Stefano Cordiner $^{1}$, Vincenzo Mulone ${ }^{1}$ and Ferdinando Pasqualini ${ }^{1}$ \\ Marco Aimo Boot ${ }^{2}$ \\ ${ }^{1}$ University of Rome Tor Vergata, Department of Industrial Engineering, via del Politecnico 1, 00133, Rome, Italy. \\ ${ }^{2}$ Iveco Group, Electrification Technologies.
}

\begin{abstract}
The transport sector is today a major source of pollutant and greenhouse gas emissions. Fuel Cell Hybrid Electric Vehicles are a solution to reduce its environmental impact, thanks to the zero pollutant tailpipe emissions and longer driving ranges if compared with full electric vehicles. A Digital Twin of a FCHEV is developed in this study, through the assessment of models of mechanical and thermal systems within the vehicle. The Simulink/Simscape model here presented is able to support both the design choices and the test of control strategies. The results obtained allow characterizing the impact of the auxiliary systems on the driving range, whose relative value ranges from $28 \%$ to $40 \%$ of the overall energy demand depending on the ambient temperature, and the range is between $430 \mathrm{~km}$ and $356 \mathrm{~km}$ respectively for mild and cold temperature.
\end{abstract}

\section{Introduction}

Nowadays, sustainability is one of the key concepts driving the research activities on vehicles towards solutions capable of facing with global challenges, such as the limited availability of fossil primary energy sources, the global warming or the environmental pollution.

In the last decades, UE has promoted several initiatives to achieve the target of net-zero Greenhouse Gases (GHG) emissions (whose limit is 2050), to keep the global temperature increase below $2^{\circ} \mathrm{C}$ above pre-industrial levels [1],[2],[3]. In agreement with the aforementioned restrictions, automotive companies are acting to replace the conventional internal combustion engines with innovative powertrain systems fueled with cleaner energy sources (i.e. Battery Electric Vehicles BEVs and Fuel Cell Hybrid Electric Vehicles FCHEVs [4]).

PEM fuel cells, the mainstream technology for the utilization of hydrogen in the transport sector, are attractive for such applications due to the following advantages: high efficiency and durability, low noise, no tailpipe emissions other than water, and short refueling time [5],[6],[7] [8]. Applying such systems in a vehicle, often requires a battery pack, according then to a hybrid architecture, to exploit fully the potential advantages of coupled battery packs and PEM fuel cells stacks.

Numerous studies have been carried out on FCHEVs critical issues, such as the fuel cell integration and sizing, the drivetrain design, the battery pack design, the fuel storage system design, and the implementation of control strategies and component downsizing in general [7],[9].

For such purposes, design and control of components into more complicated systems, Digital Twins (DTs) of physical systems are an important tool, since experimental tests usually require high costs and longer development timings.
In many papers available in the literature, studies reported about the use of computational models to represent the behavior of single components into a hybrid fuel cell powertrain system. Wang et al. [10] proposed a Digital Twin of a PEMFC starting from a 3D model whose results were used to train a machine learning simpler model. Similarly, authors in [11] implemented a datadriven DT for the prediction of fuel cell Remaining Useful Life (RUL).

In other papers, the attention was focused on Energy Management Systems (EMSs), proposing different control strategies to manage the power splitting between the different energy sources (FC, batteries and ultracapacitors). Simplified models have been adopted to study optimal control strategies for different purposes, including the maximization of efficiency or system downsizing. More in general, control strategies in the literature fall into different classes, such as rule-based strategies [12],[13], model predictive control (MPC) strategies [14],[15] and other categories.

In this study, a Digital Twin of a whole FCHEV, including powertrain and auxiliary system, is proposed to represent its actual behavior according to a driving cycle. All the important sub-systems to characterize the vehicle from the energy standpoint are considered, including the battery pack, the fuel cell stack, the thermal system, the hydrogen and air supply systems, and the HVAC system. In this paper the model is applied to discuss a fuel cell range extender control strategy based on rules defined similarly to the paper by Fernández et al. [16] [17].

Based on the above-mentioned papers, this paper aims at proposing a complete FCHEV digital twin - developed in the Matlab/Simulink/Simscape framework - with the aim of filling the following literature gaps:

- Highlighting the influence of auxiliary systems on the vehicle performance.

\footnotetext{
* Corresponding author: edoardo.cennamo@alumni.uniroma2.eu
} 
- Highlighting the importance of a complete vehicle digital twin to elaborate power splitting strategies.

- Introducing a virtual platform for testing and designing sustainable FCHEVs.

The article has the following structure. Section 2 presents a description of the Digital Twin representing a FCHEV; numerical results and related discussion are reported in Section 3 and finally Section 4 highlights the main conclusions and future perspectives.

\section{Modelling approach}

The basic layout of the considered fuel cell hybrid electric vehicle (light-medium duty commercial vehicle) is shown in Fig. 1. The powertrain includes a $130 \mathrm{~kW}$ electric motor supplied by two energy sources: the primary one is a 104 Ah battery pack, whose rated voltage is $350 \mathrm{~V}$, and a secondary energy source based on a $99 \mathrm{~kW}$ rated power PEM fuel cell. In particular, a parallel layout between the $\mathrm{FC}$ and the batteries is chosen and a DC-DC converter is used to connect the FC to the DC-bus.

The hybrid powertrain is linked to the "Vehicle dynamics" block to represent the mechanical and dynamic behavior of the vehicle (i.e. body, tires, brake system and drive axles) and the "Drive cycle data" block used to model the driver, through a PI controller receiving the speed error and converting it into a torque request signal.

As temperature is one of the main parameters determining the components behavior, thermal capacity and heat transfer effects are represented with detail into a thermal system model. The thermal system includes a radiator, a circulating pump, pipes, by-pass valves, and a fan to control the air flow to the radiator. A chiller is also considered to control the temperature of batteries, characterized by strict requirements. The HVAC (Heating, Ventilation and Air Conditioning) system is also modeled to satisfy the comfort requirements of the cabin.

The hydrogen supply system is represented with a tank, pipes and pressure regulators for pressure control purposes at the stack, including the purge feature. Air supply system and power electronics sub-systems are also represented with simplified sub-models taking into account efficiency, toward the calculation of thermal losses and electric power absorption.

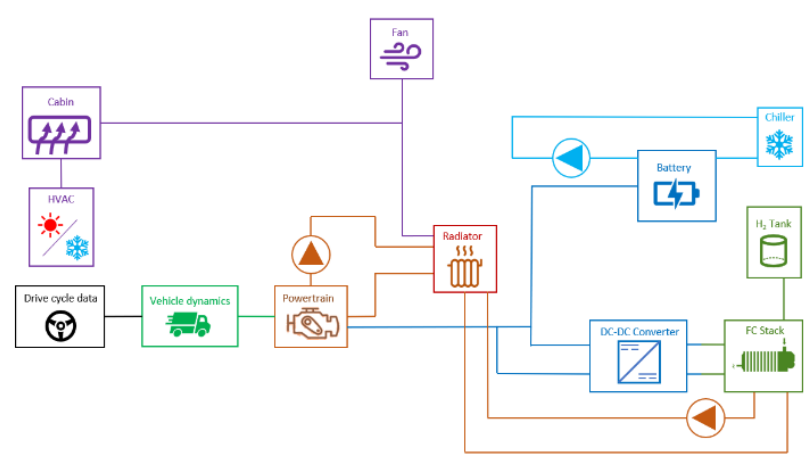

Fig. 1 FCHEV layout scheme.

\subsection{PEM Fuel cell}

The technical specifications of the Fuel Cell System (FCS) considered in the FCHEV Digital Twin are listed in Table 1.

Table 1. Fuel Cell system specifications [18].

Rated Electrical Power

$99 \mathrm{~kW}$

Operating Current

0 to $500 \mathrm{~A}$

Operating Voltage

180 to $360 \mathrm{~V}$

Peak Efficiency

$55 \%$

Coolant

Ethylene glycol and water mixture

Operating temperature $67^{\circ} \mathrm{C}$

Dimensions L $\mathrm{x}$ W x H

$955 \times 1525 \times 345 \mathrm{~mm}$

Mass

$327 \mathrm{~kg}$

Volume

$502 l$

Fig. 2 shows voltage, net power and efficiency of the FCS as a function of the net current.

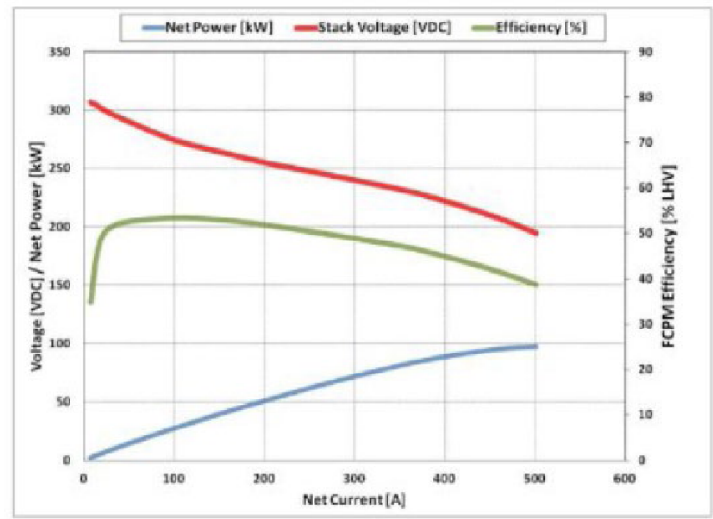

Fig. 2 FCS Datasheet performance[18].

Considering the fuel cell efficiency, the heat losses are defined by the following equation [8]

$$
Q_{\text {gen }}=P_{\text {tot }}\left(\frac{1}{\eta_{\text {stack }}}-1\right) \text {. }
$$

The layout of the FCS cooling systems is provided in Fig. 3. The required coolant flow rate is provided by a variable speed centrifugal pump, feedback controlled to target the coolant temperature value at the stack inlet. The heat power disposed from the FC is dissipated with an aircooled radiator. The air mass flow rate is supplied by fans mounted in the front section of the radiator. A three-way valve allows the control of coolant flow splitting beetween radiator and by-pass, to manage the transient period. 


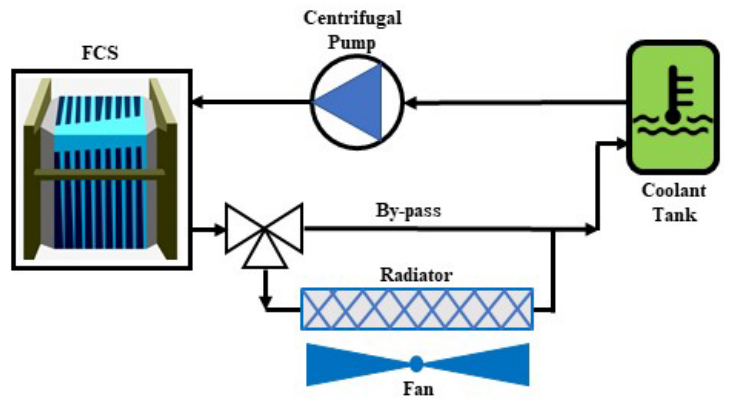

Fig. 3 FCS layout cooling system.

The Fuel Cell System is controlled to work at the optimum temperature as specified by manufacturer to maximize the conversion efficiency. The functional dependence of efficiency and power output on temperature and current is shown in Fig. 4 and Fig. 5. Moreover, a preheating feature is considered at cold start to further increase the hydrogen conversion efficiency.

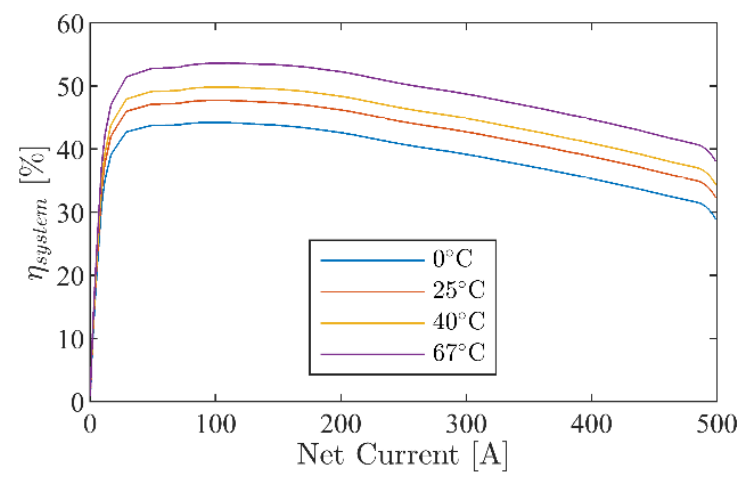

Fig. 4 System Efficiency vs Stack Temperature.

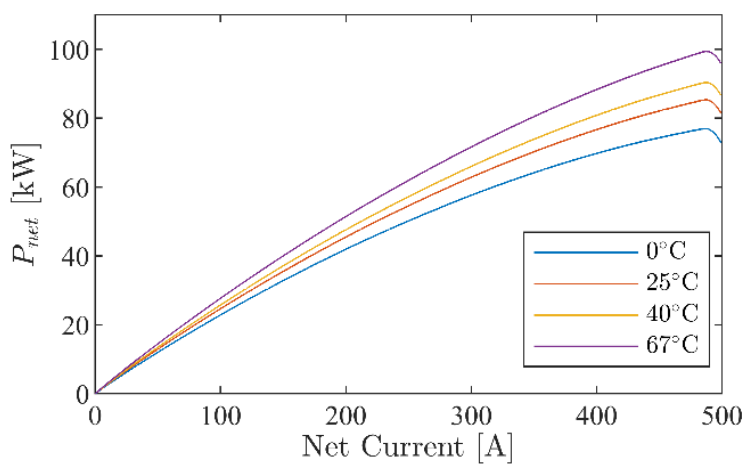

Fig. 5 Net Power vs Stack temperature.

\section{Results and discussion}

The analysis of results is divided into two sections. In the first one, results of a standard case are reported and commented to highlight the features of the vehicle model. In the second one, two case studies are presented, to show the differences in terms of range and auxiliary system power absorption characteristics, affecting the vehicle performances depending on:
- Ambinet temperature (winter, summer, standard case).

- Battery capacity, considering two battery packs in parallel.

\subsection{Standard case}

In this study the standard driving cycle WLTP is used as input datum. The cycle considers an aggregation of different driving conditions (from urban to extra-urban in terms of speed and acceleration ranges) with a total distance covered of $23 \mathrm{~km}$ and a duration of $30 \mathrm{~min}$ (1800s). The simulations are carried out according to a sequence of the WLTP until the hydrogen contained in the two 700 bar pressurized hydrogen tanks are discharged and the battery SOC is back to the starting value.

A range extender rule-based strategy has been selected to control the power splitting between the FC system and the battery. The control strategy is based on the battery SOC monitoring, with an upper and a lower bound values set a priori, determining the conditions to start the operation of the FC system. Whenever the upper bound is reached, the operating conditions are set as "discharge phase", according to which batteries operate as the exclusive energy source and fuel cell stops operating. In Fig. 6 the SOC profile for the Standard case $\left(T_{a m b}=\right.$ $25^{\circ} \mathrm{C}$ ) simulation is shown: $S O C_{\min }$ and $S O C_{\max }$ are set to $45 \%$ and $70 \%$ respectively.

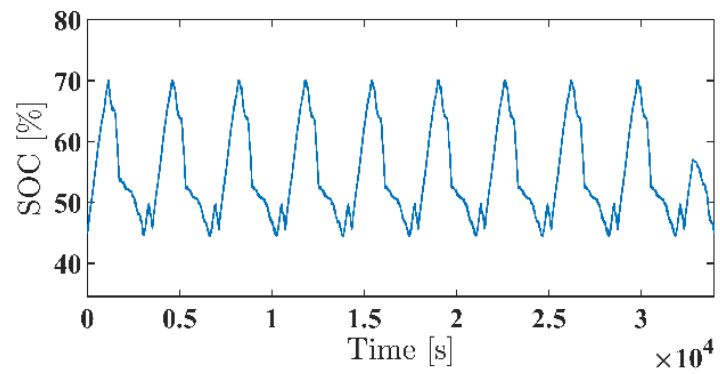

Fig. 6 Battery State Of Charge.

During the "recharge phase", the DC-DC converter is controlled by its output current, set to a constant value, meaning that the power output, as well as the input given by the fuel cell system, is not constant due to a voltage variation.

The powertrain control strategy in terms of SOC bound values and recharge current supplied by the FC system is important as the recharge efficiency of a battery is not ideal, and charging efficiency depends on the Depth of Discharge (DOD) and recharge current set-point. To avoid excessive efficiency drops, a rather strict lower bound of the SOC value (at a DOD of $35 \%$ ) with a constant recharge current set to $104 A$ ( $1 C$ rate) is implemented. The latter represents an upper bound, since during operating conditions if the traction motor requests power, the net current at the battery is decreased. The value of $104 \mathrm{~A}$ is also chosen according to a conservative approach, to not affect the battery state of health, avoiding degradation due to high load cycling.

Fig. 7 presents the profile of the system efficiency and stack efficiency over a full simulation test. 
In Fig. 8 and Fig. 9 a detail of system as well as stack efficiencies and $\mathrm{FC}$ temperature are shown respectevely. It is worth noting that during the warm-up, efficiencies are lower than the rated values. Again in Fig. 9 it can be observed that the FC cooling system control operates in order to maintain the temperature at the set point value (the plateau in the figure).

During the discharge phase, the FC temperature partially cools down, keeping values closer to the design ones, and enabling a faster warm-up during the following charging phase (Fig. 10).

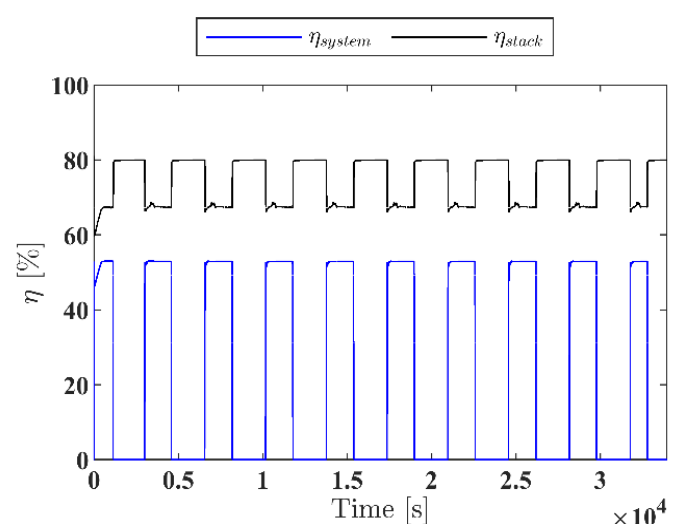

Fig. 7 System efficiency vs stack efficiency.

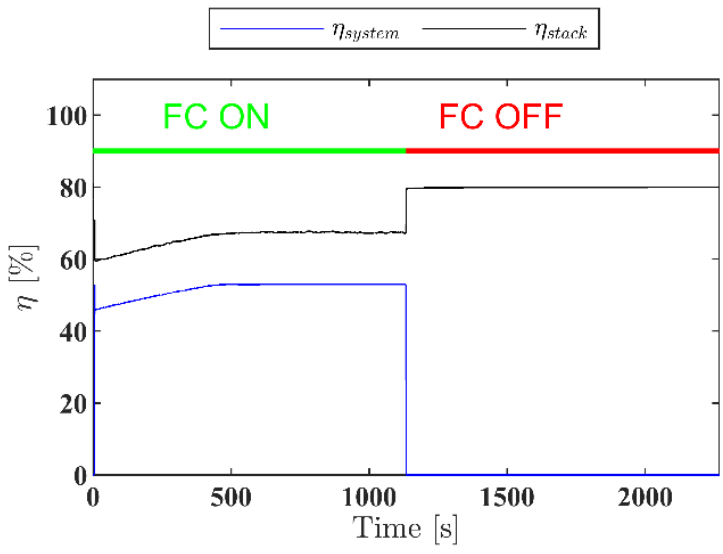

Fig. 8 Detail of System and Stack efficiencies - start up.

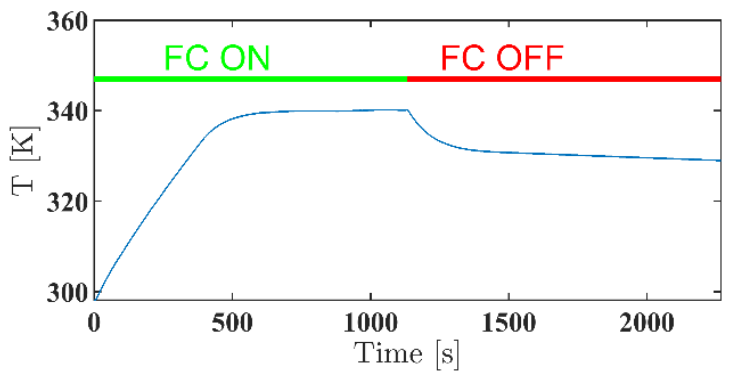

Fig. 9 Detail of FC temperature - start up.

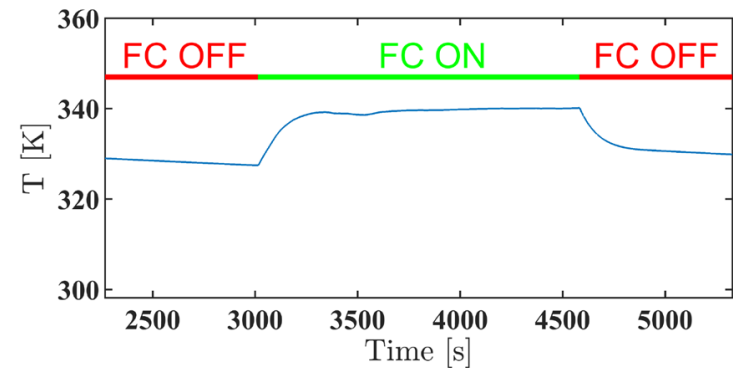

Fig. 10 Detail of FC temperature - steady state.

A detail of the power absorbed by the Fuel Cell internal auxiliaries over a single charge phase is reported in Fig. 11.

An almost constant auxiliaries request of about $10 \mathrm{~kW}$ is observed over the whole FC operating time and the Fuel cell System efficiency is maintained in the maximum efficiency range, as already commented for Fig. 2 .

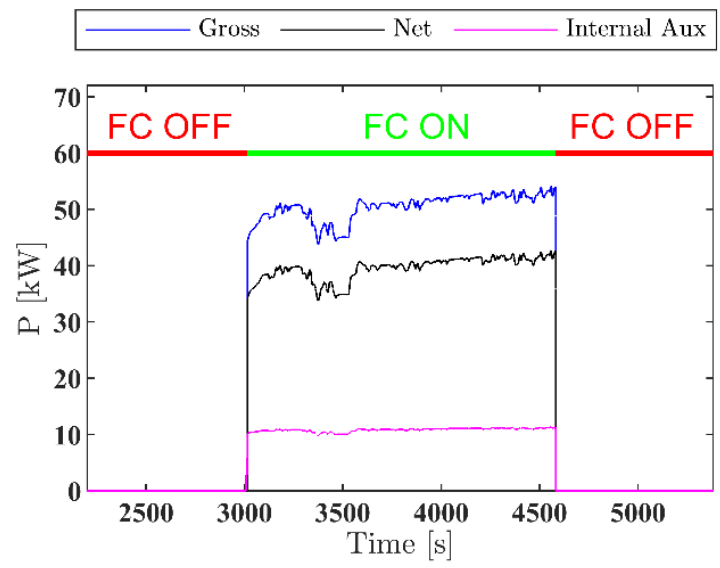

Fig. 11 Detail of Fuel cell power distribution.

As mentioned for the FC system, temperature control is also mandatory for the correct operation of other vehicle sub-systems, such as the battery packs and the electric motor. On the one hand, it affects the behavior of the components (degradation, useful life), and on the other hand, its management results into an additional power demand which must be supplied by vehicle energy sources. Fig. 12 shows the battery pack temperature during the whole simulation: the peaks of temperature over $40^{\circ} \mathrm{C}$ (but always below $45^{\circ} \mathrm{C}$ ) correspond to the last stretch of the WLTP, the extra-urban sub-cycle, which requires a greater traction power.

An important observation concerns the control logic of the chiller, since it is used for both the HVAC and the battery cooling system. The refrigerant gas flow rate is split depending on the temperature of the battery according to the following strategy:

- If $T_{\text {battey }}<35^{\circ} \mathrm{C} \mathrm{HVAC}$ gets the entire refrigerant flow rate.

- If $35^{\circ} \mathrm{C}<T_{\text {battey }}<40^{\circ} \mathrm{C}$ the coolant flow rate is split between HVAC and battery cooling system.

- If $T_{\text {battey }}>40^{\circ} \mathrm{C}$ the battery cooling system has priority in terms of refrigerant flow rate. 


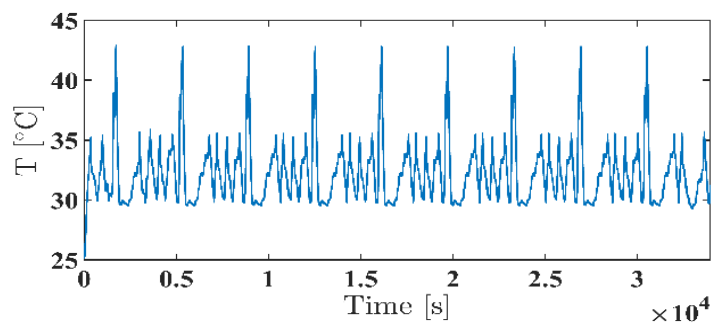

Fig. 12 Battery Packs Temperature.

Fig. 13 describes the energy fluxes distribution among the different components and the split between the auxiliary loads. It can be observed that the total energy requested by all the vehicle auxiliaries (not considering the FC internal Balance of Plant) is approximately $6.5 \%$ of the entire energy demand. The FC auxiliaries have also a great influence on the overall energy consumption, assessing their share at around $21.6 \%$ of the total demand. A significant amount of energy is also lost during the charing/discharging processes from the battery (about $6.8 \%$ ). Overall, the traction accounts for $65.1 \%$ of the total energy consumption highlighting the significant impact of the other components in the global Balance of Plant (BoP) of the vehicle. Among all the auxiliaries, the most demanding are the chiller, the FC cooling system, and the motor fan, all involved in the thermal management of the vehicle system components.

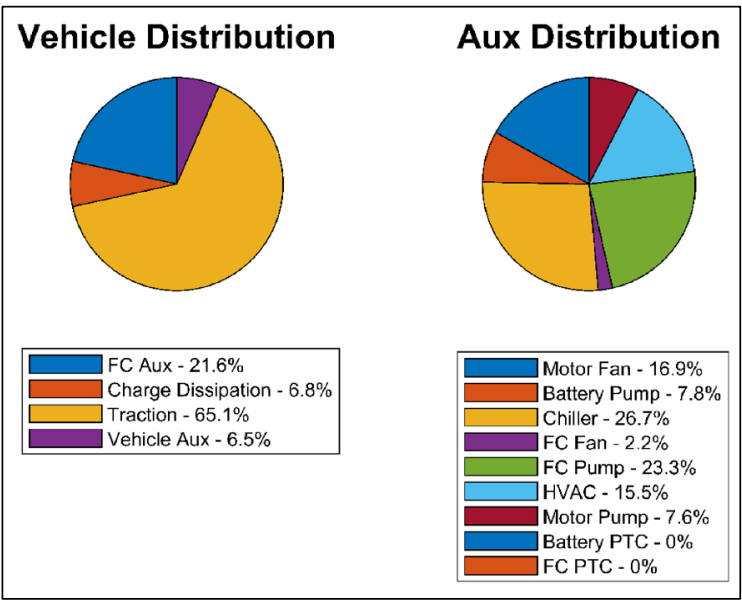

Fig. 13 Vehicle energy distribution $-T_{a m b}=25^{\circ} \mathrm{C}$.

\subsection{Case study: Environmental Temperature influence}

In order to highlight the influence of the ambient temperature on the vehicle performance and on the distribution of energy demand among auxiliaries, three different operating conditions are tested, and specifically the external air temperature has been set to $25^{\circ} \mathrm{C}$ (Standard case, equal to the previous one), $40^{\circ} \mathrm{C}$ (Summer case) and $0^{\circ} \mathrm{C}$ (Winter case).

Fig. 14 shows the results for the summer case. As expected, due to the increased power needed to cool the cabin, the portion of energy requested by vehicle auxiliaries is greater than standard case $(7.9 \%$ of the overall energy demand against $6.5 \%$ ).
A similar behavior, even more evident, is obtained for the Winter case, shown in Fig. 15. In fact, the lower ambient temperature leads to the required use of the PTCs for the battery and the FC system warming-up, as well as the cabin requests greater power $\left(\Delta T=25^{\circ} \mathrm{C}\right.$ respect to $\Delta T=15^{\circ} \mathrm{C}$ for summer case ) to maintain the set-point temperature. So, vehicle auxiliaries reach a overall impact of $18.6 \%$ on the overall energy demand.

The performance parameters commented are summarized in Table 2 by the variation of "Vehicle Aux" percentage between the three cases, and the consequent change in the estimated vehicle range considering the same amount of hydrogen available.

Table 2 Season results comparison.

\begin{tabular}{cccc} 
& $T_{a m b}\left[{ }^{\circ} \mathrm{C}\right]$ & $E_{\text {Aux, Total }}[\%]$ & Range $[\mathrm{km}]$ \\
\hline Winter & 0 & 18.6 & 355.76 \\
Standard & 25 & 6.5 & 429.55 \\
Summer & 40 & 7.9 & 422.38 \\
\hline
\end{tabular}

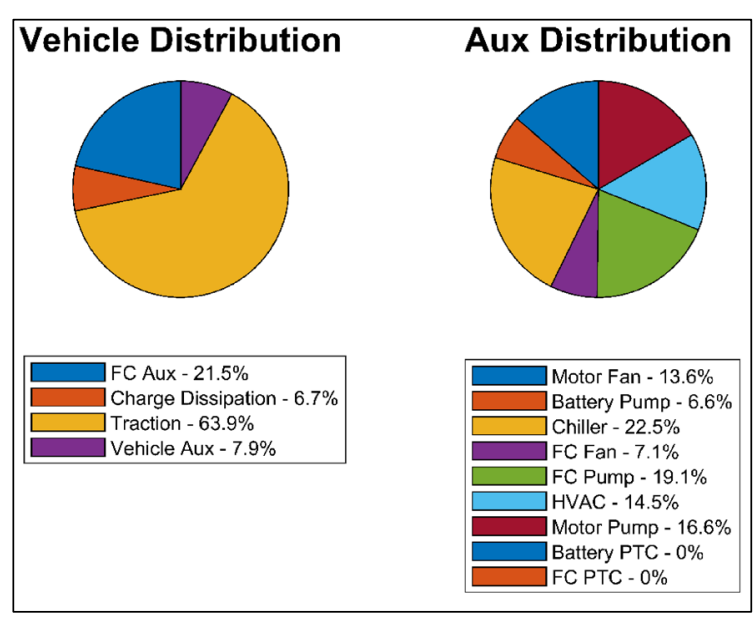

Fig. 14 Vehicle energy distribution $-T_{a m b}=40^{\circ} \mathrm{C}$.

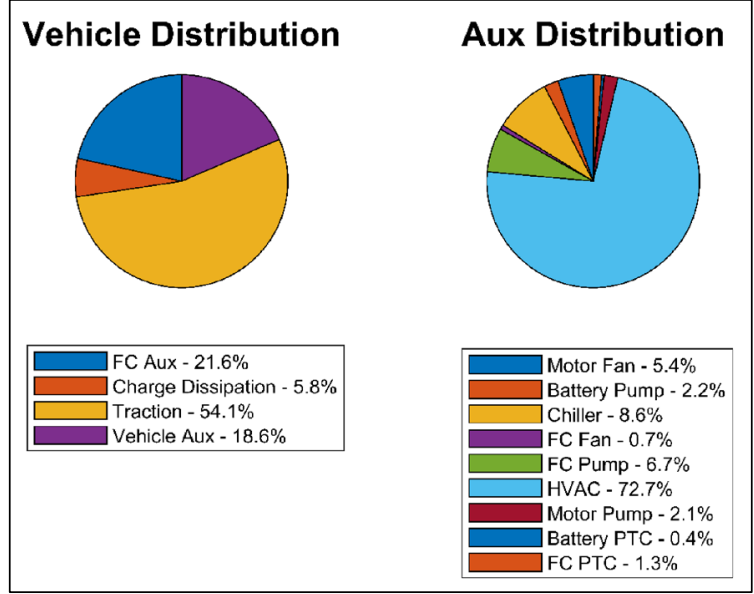

Fig. 15 Vehicle energy distribution $-T_{a m b}=0^{\circ} \mathrm{C}$.

\subsection{Case study: Battery Oversizing}

The model developed can be used also for the test of different vehicle configurations. In this section, starting from the single battery pack of the original vehicle, the 
possibility of increasing the battery capacity by using two of the $104 \mathrm{Ah}$ modules in parallel is tested to evaluate the impact on the vehicle range. The standard case is chosen to test the increased battery size. The recharge current is kept at $104 \mathrm{~A}$, therefore halvening the C-Rate with respect to the reference case. Then, heat losses are reduced. Fig.16 shows the total energy distribution obtained for the new configuration. As expected, the fraction of energy required to run vehicle auxiliaries is smaller, due to a relevant reduction of the chiller energy consumption during the whole simulation, leading to an increase of the estimated range from $429.5 \mathrm{~km}$ to $447.3 \mathrm{~km}$.

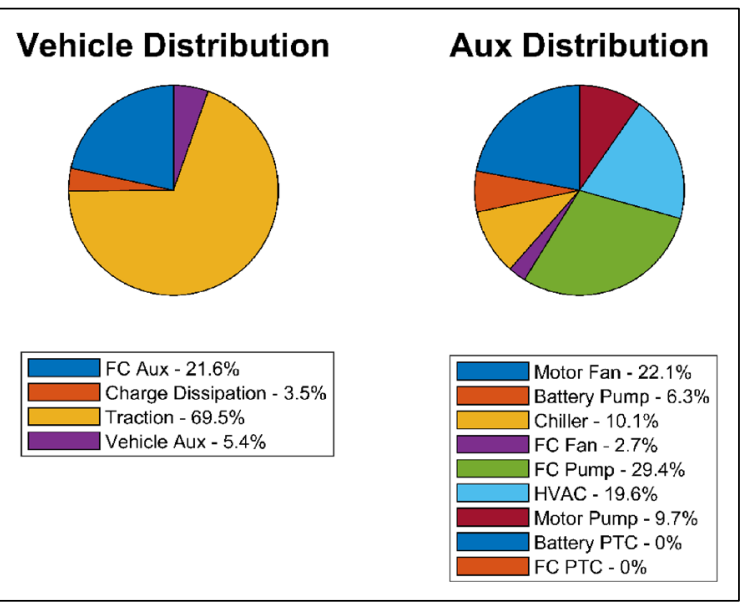

Fig. 16 Vehicle energy distribution $-T_{a m b}=25^{\circ} \mathrm{C}-208 \mathrm{Ah}$.

The lower internal heat generation of the $208 \mathrm{Ah}$ battery pack leads to a lower mean operating temperature. In fact, the temperature peaks during the extra-urban discharge phases are avoided, as shown in Fig. 17.

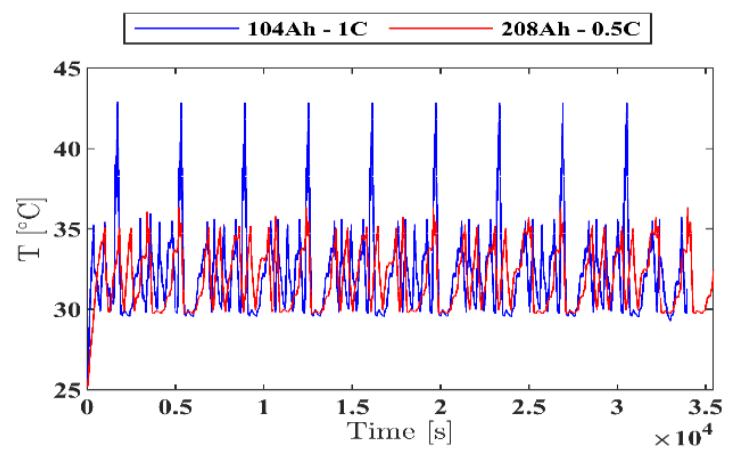

Fig. 17 Battery temperature comparison - 208/104 Ah.

It is also worth noting that comparing "charge losses" between the two cases (Fig. 13 and Fig. 16), this parameter is nearly halved in the oversized case, as evidence of the fact that the battery charge efficiency is indirectly proportional to the charging load (leaving DOD unchanged): reducing the C-rate (104 A of recharge current represents a $0.5 \mathrm{C}$ load with respect to the previous $1 \mathrm{C})$, the recharge efficiency is increased.

\section{Conclusions}

In this paper, a Digital Twin of a Fuel Cell Hybrid Electric Vehicle is proposed to analyze thoroughly the physical behavior of the mechanical and thermal systems. In particular, detailed modeling of the vehicle auxiliaries has been implemented, taking into account the HVAC, the cooling systems for the main components, and adding a chiller for a better management of the battery temperature, and fuel cell stack auxiliaries.

The vehicle computational model is able to:

- Support design development,

- Analyze the performance parameters of the vehicle.

- Test different Energy Management System control strategies.

A case study, according to which the ambient temperature is set to $0^{\circ} \mathrm{C}$ (winter case), $25^{\circ} \mathrm{C}$ (standard case), and $40^{\circ} \mathrm{C}$ (summer case), has been carried out to show the potential of the digital twin and to highlight the impact of the auxiliary system energy consumption may have on such hybrid vehicles.

The major findings of the work can be summarized according to the following points:

- The thermal management of system components and FC auxiliaries have a great impact on the overall energy consumption (with a relative impact ranging from almost $28 \%$ for the standard case up to more than $40 \%$ for the winter case).

- The external air temperature has a noteworthy influence on the vehicle range that varies from about $430 \mathrm{~km}$ in the standard case down to 356 $\mathrm{km}$ for the winter case.

- Among the auxiliaries, chiller, HVAC, FC cooling pump, and motor Fan are the most demanding.

- Doubling the battery pack of the vehicle can lead to significant improvement in terms of battery efficiency and thermal management, having positive impact also on the vehicle range. Economic consideration must be introduced to evaluate the actual convenience of increasing the storage capacity with respect to the benefits illustrated.

\section{References}

1. C. D. (EU), in (2016), pp. 6-8

2. J. Enzmann and M. Ringel, (2020)

3. K. Kuklinska, L. Wolska, and J. Namiesnik, Atmos. Pollut. Res. 6, 129 (2015)

4. G. Morrison, J. Stevens, and F. Joseck, Transp. Res. Part C Emerg. Technol. 87, 183 (2018)

5. P. Ferreira-aparicio, J. J. Conde, and A. M. Chaparro, 2 - Fundamentals and Components of Portable Hydrogen Fuel-Cell Systems (Elsevier Inc., 2018)

6. M. Muthukumar, N. Rengarajan, B. Velliyangiri, M. A. Omprakas, C. B. Rohit, and U. K. Raja, Mater. Today Proc. 45, 1181 (2021) 
7. A. G. Olabi, T. Wilberforce, and M. Ali, 214, (2021)

8. P. T. Moseley, Fuel Cell Systems Explained (2001)

9. M. Ogburn, D. J. Nelson, W. Luttrell, B. King, S. Postle, and R. Fahrenkrog, SAE Tech. Pap. 2000, (2000)

10. B. Wang, G. Zhang, H. Wang, J. Xuan, and K. Jiao, Energy AI 1, 100004 (2020)

11. S. Meraghni, L. S. Terrissa, M. Yue, J. Ma, S. Jemei, and N. Zerhouni, Int. J. Hydrogen Energy 46, 2555 (2021)

12. T. C. Do, H. V. A. Truong, H. V. Dao, C. M. Ho, X. D. To, T. D. Dang, and K. K. Ahn, Energies 12, (2019)
13. S. Changizian, P. Ahmadi, M. Raeesi, and N. Javani, Int. J. Hydrogen Energy 45, 35180 (2020)

14. Y. Zhou, H. Li, A. Ravey, and M. C. Péra, J. Power Sources 451, (2020)

15. Y. Zhou, A. Ravey, and M. C. Péra, Energy Convers. Manag. 229, (2021)

16. R. Á. Fernández, F. B. Cilleruelo, and I. V. Martínez, Int. J. Hydrogen Energy 41, 4808 (2016)

17. R. Álvarez Fernández, S. Corbera Caraballo, F. Beltrán Cilleruelo, and J. A. Lozano, Renew. Sustain. Energy Rev. 81, 655 (2018)

18. https://pdf.directindustry.it/pdfen/hydrogenics/hypm-hd-90/33492-420317.html, (n.d.) 